*Doutor em Administração pela Universidade Nove de Julho (UNINOVE). Mestre em Administração pela Universidade Estadual de Londrina (UEL). Especialista em Filosofia Política e Jurídica pela Universidade Estadual de Londrina (UEL). Especialista em Filosofia Moderna e Contemporânea pela Universidade Estadual de Londrina (UEL). Bacharel em Direito pela Universidade Estadual de Londrina (UEL). Graduado em Administração pela Pontifícia Universidade Católica do Paraná (PUCPR). Email: ricardo.favoreto@hotmail.com

**Doutor em Ciências Sociais pela Universidade Estadual de Campinas (UNICAMP). MEstre em Ciência Política pela Univerisdade Estadual de Campinas (UNICAMP). Graduado em Administração de Empresas pela Fundação Armando Alvares Penteado (FAAP). Email: ajnogueira@ usp.br

***Doutor em Filosofia pela Universidade Estadual de Campinas (UNICAMP). Mestre em Filosofia pela Universidade Estadual de Campinas. (UNICAMP). Especialista em Direito Eleitoral e Processo Eleitoral pela Claretianos (CLRT). Especialista em Filosofia pela Universidade Estadual de Londrina (UEL). Graduado em Direito pela Faculdade Pitágoras de Londrina (FPL). Graduado em Filosofia pela Univeridade Estadual de Londrina. Email: cbannwart@, hotmail.com

\section{Problematizando o Conceito de Responsabilidade SOCIAL EMPRESARIAL: IMPLICAÇÕES DE UMA LEITURA MULTIDisCiPLinAR}

\author{
REFlecting on CoRporate Social Responsability: \\ IMPLICATIONS OF A MULTIDISCIPLINARY READING
}

\section{Ricardo Lebbos Favoreto* Arnaldo José França Mazzei Nogueira** Clodomiro José Bannwart Júnior**}

Como Citar: NOGUEIRA, Arnaldo José França Mazzei. BANWWART JÚNIOR, Clodomiro José. FAVORETO, Ricardo Lebbos.Problematizando o conceito de responsabilidade social empresarial: implicações de uma leitura multidisciplinar. Scientia Iuris. Londrina, v.24, n.1, p. 55-77, março 2020. DOI 10.5433/21788189.2020v24n1p55. ISSN 2178-8189.

Resumo: A responsabilidade social empresarial (RSE), em décadas recentes, ganhou amplo espaço na pesquisa acadêmica e na prática gerencial. Apesar de estar em evidência, seu conceito ainda suscita dúvidas. De que realmente se trata a RSE? Como se relacionam as partes envolvidas? Sujeita-se a ideia que representa a algum tipo de controle? Com a difusão da RSE, o conceito anuviou-se, adquirindo sentidos diversos, conforme as resultantes dos propósitos em questão. Visando-se compreendê-lo melhor, procede-se neste artigo a uma leitura multidisciplinar da RSE. Utiliza-se, para tanto, de aportes da Administração, do Direito e da Filosofia, com enfoque no pensamento habermasiano. A Teoria da Ação Comunicativa de Habermas possibilita que se direcione à RSE uma visão crítica, extensora das acepções que a ela usualmente se atribuem. Trata-se de pesquisa teórica, cujo objetivo é discutir a RSE reflexivamente e por ângulos variados. Aponta-se para a necessidade de investir na inteligibilidade conceitual da RSE.

Palavras-chave: Responsabilidade social empresarial. Gestão empresarial. Direito. Habermas. Teoria da ação comunicativa.

Abstract: In recent decades, corporate social responsibility (CSR) has gained headway in academic research and managerial practice. Although CSR has become notorious, its concept still raises doubts. What is CSR really about? How do the parties involved in CSR relate? Is the concept of CSR influenced by any kind of control? With the spread of CSR, its concept became unclear, attracting different meanings that emerged as the results of the forces involved. In order to better understand the concept, 
this article presents a multidisciplinary reading of CSR. For this purpose, the contributions of three areas of knowledge are used: Business, Law and Philosophy, focusing on Habermasian thought. Habermas' Theory of Communicative Action makes it possible to take a critical view on CSR, extending its traditional meaning. This essay faces some important questions that surrounds CSR and brings attention to the necessity of consciously improve its concept.

Keywords: Corporate social responsibility. Business management. Law. Habermas. Theory of communicative action. 


\section{INTRODUÇÃO}

A RSE é um assunto francamente atual, que, em décadas recentes, ganhou amplo espaço na pesquisa acadêmica e na prática gerencial. Inicialmente ligada ao altruísmo, a RSE temse tornado, cada vez mais, um mecanismo utilizado pelas organizações para a consecução de vantagem competitiva. Já há algum tempo, pesquisas demonstram haver uma relação positiva entre desempenho social e desempenho financeiro (e.g., BELKAOUI, 1976). Indicativos contrários tampouco constituem novidade (e.g., DAVIDSON; WORRELL, 1988). A busca pelo estabelecimento de relações, sejam elas quais forem, é procedida, geralmente, por um carril instrumental. A RSE definitivamente ingressou na ordem do dia das organizações como matéria estratégica.

Como muitos dos fenômenos da gestão, a RSE é também apreciável pelo Direito, tanto do ponto de vista filosófico quanto do legal. Do primeiro porque a RSE deriva diretamente de valores éticos e princípios morais; do segundo porque a ação de RSE tornou-se fato jurídico relevante, que, dada a grandeza dos seus efeitos no mundo, convém regular juridicamente. Com frequência, a RSE compartilha espaço com questões de direitos humanos (e.g., GIULIANI, 2016), direito do consumidor (e.g., IDEC, 2011), direito ambiental (e.g., AARONSON, 2005). A imprecisão conceitual que envolve o fenômeno pode, no entanto, inviabilizar que, na ordem jurídica, se qualifique com clareza um ato como responsável do ponto de vista social. A aproximação entre RSE e Direito é feita, assim, sempre sob o risco de se gerarem resultados estéreis. O Direito não apreende o conceito na sua integralidade.

Visando-se ampliar a compreensão do conceito, propõe-se neste artigo uma leitura multidisciplinar da RSE, com o subsídio de três áreas do conhecimento: a Administração, o Direito e a Filosofia, com enfoque no pensamento de Jürgen Habermas. Trata-se de pesquisa exploratória, conduzida por intermédio de levantamento bibliográfico. Nas duas primeiras seções, aborda-se a RSE, respectivamente, na Administração e no ordenamento jurídico brasileiro. Na seção subsequente acresce-se à leitura um viés alternativo, mediante o aporte da Teoria da Ação Comunicativa (TAC) de Habermas. Extraem-se dela duas categorias de ações, a comunicativa e a estratégica, a partir das quais se empreende uma releitura crítica do conceito de RSE.

\section{RSE: DE CONTRAPESO A FORTALECIMENTO INSTITUCIONAL}

Conquanto não se possa desprezar o influxo do indivíduo sobre as resultantes institucionais (ver, por exemplo, Chin, Hambrick, e Treviño (2013), sobre a influência dos valores dos CEOs nas práticas de RSE), cumpre sublinhar que, quando se tem em pauta a RSE, a unidade analítica focalizada não é, como no campo da ética, o indivíduo, mas a organização. A ética em questão é o apólogo que se convencionou denominar ética organizacional. Basicamente, o que possibilita falar em tal ética é a personificação da organização, em decorrência de que, qual o indivíduo, a organização é avaliada socialmente por sua conduta, sendo atribuídos aos seus atos, comunitariamente, juízos 
de valor. Ao modo da evolução da responsabilidade individual, a responsabilidade corporativa tem transcendido as fronteiras organizacionais espaço-temporais tradicionais, para abranger atividades posicionadas ao longo da cadeia de valor e mesmo decisões tomadas por gerações passadas de gestores (SCHREMPF-STIRLING; PALAZZO; PHILLIPS, 2016).

Nasce a RSE como contrapeso ao imenso poder concentrado pelas organizações, crescente desde a Revolução Industrial. O incômodo por conta dessa concentração foi disseminado por eventos marcantes, como a publicação do internacionalmente propalado "When corporations rule the world", de David Korten (1995).

O foco crítico da discussão sobre RSE não é hoje, no entanto, o mesmo de algumas décadas atrás. Se o desafio era, inicialmente, incutir na sociedade a ideia de um dever ético das organizações que sobrexcedesse o cumprimento do objeto social, hoje, com a consolidação da RSE como instrumento de gestão estratégica, o desafio amplificou-se. Tornou-se menos pragmático e mais reflexivo, até porque os casos de RSE respaldam a ideologia de mercado justo, que tende a justificar o mesmo sistema no qual se manifestaram os problemas que tornaram a RSE necessária, a economia de mercado (HAFENBRÄDL; WAEGER, 2017). Tinha-se por objetivo uma mudança de mentalidade, o que ocorreu. Agora, não se sabe se podemos confiar nos parâmetros instituídos, uma vez que, constituindo-se como meio para a obtenção de vantagem competitiva, a RSE passa a ser concebida como variável da qual depende o êxito e, enquanto tal, deve ser controlada.

Seu próprio conceito é alvo de manejo pelas organizações. Aquilo que comunitariamente se entende por RSE orienta aquilo que se entrega como RSE. Interessa às organizações, assim, conformar o conceito de modo que, sendo passível de alinhamento estratégico, lhes seja instrumentalmente útil. Por consequência, estabelecendo-se a RSE em ambiente competitivo, nela se radica, inevitavelmente, a função excludente. Isso significa que o compartilhamento orientado do seu conceito acarreta vantagem de umas organizações sobre outras, prevalecendo aquelas que conseguem legitimação social.

Não raro, principalmente quando se trata de grandes corporações, a legitimidade não é produto de um ricochete passivo às pressões do ambiente. Distintamente, é resultado calculado, que, num movimento de trás para frente, serve de base para a coordenação de esforços cuja finalidade é o delineamento inteligente (do ponto de vista da empresa) do conceito de RSE. Mais que entendimento, o que interessa é a percepção. Como a comunidade percebe a RSE? É a percepção que direciona o juízo, muitas vezes prescindindo-se da clareza intelectual demandada. Campanhas publicitárias vertiginosas não explicam a RSE; apenas fazem que o conceito seja formado a partir da percepção. A empresa busca atender a uma expectativa de comportamento social, colhendo, com essa atitude, reconhecimento público como forma, por exemplo, consoante relatado em Mun e Jung (2018), de alinhar-se com as exigências de investidores institucionais globais.

O dilema mais notório em torno do conceito de RSE não é recente. Foi estabelecido, de um lado, por ideias que restringem a responsabilidade organizacional ao cumprimento das finalidades do objeto social e, de outro, por ideias que a estendem para além da execução dessas finalidades. O popular artigo de Milton Friedman evidencia a medida dessa distensão, e não é 
preciso mais que o título para captá-la: “A responsabilidade social de um negócio é aumentar seus lucros" (FRIEDMAN, 1970). Enquanto se digeriam suas reverberações, Keith Davis elencava, em seu também conhecido artigo, ideias bastante distintas - como a necessidade de se considerarem os custos sociais da atividade empresarial - que, já à época, pareciam atrair a convergência de um número expressivo de partes ligadas ao tema (DAVIS, 1975).

Da década de 1970 em diante, algumas ambiguidades foram esvaziadas, mas, com a crescente complexidade a envolver a questão, outras surgiram. Na década de 1980, a popularização da teoria dos stakeholders, movida, entre outras causas, pela publicação, em 1984, do clássico "Strategic Management: a Stakeholder Approach", de Freeman, reforçou o interesse pela RSE. A teoria dos stakeholders colocou a RSE na mira da ação estratégica. Seu princípio postula que a atuação organizacional deve levar em conta as demandas dos stakeholders. Esses se constituem por "qualquer grupo ou pessoa cujos interesses podem afetar ou ser afetados pela realização dos objetivos da organização" (FREEMAN, 1984, p. 46). A teoria expandiu, assim, os limites do próprio conceito de organização, ao assumir que a organização não existe para satisfazer apenas aos seus proprietários, mas às partes que, de alguma forma, com ela se relacionam.

Correntemente, à RSE têm-se agregado vias sortidas. Abordagens ligadas, por exemplo, à filantropia (e.g., CAMPBELL; MOORE; METZGER, 2002), cidadania corporativa (e.g., SISON, 2011), performance (e.g., CARROLL, 1979) delinearam de forma bastante plástica o campo teórico em questão. Tal permissividade dificultou fixar no termo uma definição. Isso, se por um lado, permitiu que sua construção conceitual se constituísse de modo participativo, por outro, mitigou seu lastro, tornando-o demasiadamente suscetível aos modelamentos que lhe impingiram as organizações. Na Administração, fizeram-se comuns questões como as encontradas em McWilliams e Siegel (2001, p. 117): “empresas socialmente responsáveis superam ou não outras empresas que não se adequam aos mesmos critérios sociais?" e "quanto uma empresa deve gastar em RSE?".

Agora, a despeito das variações, parece que, tradicionalmente, a concepção de RSE disseminou-se seguindo algumas ideias-chave. O modelo proposto por Carroll (1979), um dos mais conhecidos do campo, serve de exemplo. Propõe-se, de antemão, que uma definição de RSE que contemple todas as obrigações que uma empresa tem para com a sociedade deve incorporar quatro categorias de desempenho: econômica, legal, ética e discricionária. A figura representativa do modelo o autor denomina "responsabilidades sociais totais".

Da noção tradicional de RSE, da qual o modelo é mostra, pelo menos três pontos chamam atenção. Primeiro, que o conceito de RSE constitui-se no contexto economicista contemporâneo, seu elemento econômico sobressaindo entre os demais. Depois, que, embora tenha surgido com a finalidade explícita de contrapesar o poderio desenvolvido pelas organizações, a RSE não se constituiu como antinomia à situação vigente, mas, antes, como instrumento de exercício estratégico para a intensificação do poder empresarial. A soberania corporativa, assim, não mais é exercida arbitrariamente, mas por intermédio de um instrumento, a RSE, cuja ideação é influenciada pelas empresas. Chega-se aí ao terceiro ponto. Na medida em que se imprime no conceito de RSE a 
conotação de "algo além", ou seja, que se convenciona ser a RSE algo ligado a afazeres extras, cria-se um espaço conceitual elástico, editável por quem dele puder se apropriar.

Não soa estanho nomear responsabilidade aquilo que, mesmo na presença de pressão social, carecendo de clareza, é deixado ao julgamento e à escolha discricionais? É como Carroll (1979) se refere à categoria de responsabilidades qualificadas como discricionárias. Não um contrapeso, mas um mecanismo de tonificação empresarial é o que talvez a RSE tenha-se tornado. O "algo além" pode não ter sido uma conquista social, mas um passe-livre para que, em contrapartida às demandas sociais por elas mesmas criadas ou influenciadas, as organizações se justificassem de acordo com o que lhes convém. Em boa medida, para retirar o caráter subjetivista que a empresa empresta à RSE, é fundamental que a própria empresa seja compreendida no arcabouço mais amplo de uma teoria da sociedade, acrescido de estruturas legais que o plano internacional impõe. Vale rememorar que a transnacionalização dos negócios tem evidenciado o esmaecimento do poder regulatório dos Estados e a consequente emersão de lacunas normativas (WAGNER; SEELE, 2017).

Duas questões ajudam a entender esse efeito: que ator hoje poderia ocupar o papel da empresa na condução dos programas sociais em vigor? Coeteris paribus, são esses programas indispensáveis à sociedade? Se as respostas forem, respectivamente, "não sabemos" e "sim", já se pode ter ideia do poder que a RSE conferiu às empresas, o mesmo que frequentemente se acha que delas se retirou.

\section{A RSE POSTA SOB A PERSPECTIVA LEGAL BRASILEIRA}

A solidariedade é um valor estimulado pela ordem jurídica brasileira. Na Constituição Federal, a liberdade de atuação econômica é contrabalançada com o direcionamento imposto às suas resultantes. Já no Art. $3^{\circ}$, que, entre os dispositivos iniciais, fornece os parâmetros basilares para a exegese do texto constitucional, estipula-se como objetivo fundamental da República “construir uma sociedade justa, livre e solidária" (BRASIL, 1988). No Art. 170, que elenca os princípios gerais da atividade econômica (BRASIL, 1988), encontram-se entre eles alguns que, recorrentemente, são transformados em escopo de programas de RSE, forma sistematizada de que as empresas se valem para consubstanciar o valor solidariedade.

Os princípios norteadores de dado âmbito da ordem jurídica (no caso, o econômico) devem ser interpretados sistemicamente. Cada um é parte de um conjunto em função do qual se granjeiam seus sentidos particulares. Juridicamente, sob essa ótica, o responsável não é qualidade que se deva atribuir em virtude do desempenho de um ou outro programa, mas em contrapartida à observância ampla dos princípios constitucionais. Inteiram o rol do Art. 170: soberania nacional, propriedade privada, função social da propriedade, livre concorrência, defesa do consumidor, redução das desigualdades regionais e sociais, busca do pleno emprego e tratamento favorecido para as empresas de pequeno porte (BRASIL, 1988).

A despeito de ter-se edificado a RSE sobre parâmetros instituídos preponderantemente no plano do mercado, qualquer ação que se pretenda responsável, praticada sob abrigo do 
ordenamento brasileiro, submete-se, necessariamente, aos seus preceitos jurídicos. A evolução histórica do conceito de RSE, por via diversa, aponta para um hipotético descolamento do campo legal. É comum, em frameworks disseminados (como o contido no já citado Carroll (1979)), que as responsabilidades legais sejam consideradas apenas parte da RSE.

Subjaz a essa ideia a concepção de que a responsabilidade não é de todo alcançada pelo Direito, ou seja, a atuação empresarial pode encontrar-se um passo à frente da ordem jurídica, distendendo-se para além da determinação legal. Na outra face da moeda, estampa-se, como efeito necessário, a impertinência da responsabilização legal do ato corporativo que seja qualificado como socialmente irresponsável (acerca dos atributos de uma "percebida" irresponsabilidade social, ver Lange e Washburn (2012)). Não deixa de soar estranho o termo quando a ilação derivada da análise do conceito corrente de RSE aduz que, cumpridas as obrigações legais, cabe à empresa, como prerrogativa sua, a opção pela responsabilidade social. Função social é algo distinto de responsabilidade social.

O Código Civil brasileiro enfoca a responsabilidade sob o ângulo da responsabilidade civil. Segundo o Art. 927, a obrigação de reparar dano, essência da responsabilidade civil, é atribuída àquele que o causa, por ato ilícito (BRASIL, 2002). Tal tipo de responsabilidade implica, como pressuposto, a prevalência da represália pela reparação, que, objetivamente, presume-se preferível pela parte lesada. A ideia de responsabilidade civil não se comuta, entretanto, com a de responsabilidade social. Enquanto aquela parte de uma agenda negativa e determinada, ou seja, condiciona-se sua função à ocorrência de um evento lesivo, ficando a empresa responsável em relação à determinado alguém, esta parte de uma agenda neutra e indeterminada, ou seja, é responsabilidade que prescinde de um episódio e transcende a relação a dois. Onde se encaixa, então, a RSE na ordem jurídica?

Para essa questão, talvez não seja possível precisar uma resposta, considerado o atual conceito de RSE e sua contextualização. Parece, no entanto, que, dado o que se entende por um agir socialmente responsável, os fundamentos da RSE estariam dispersos de forma sistêmica pelo ordenamento jurídico, não se achando por completo especificamente positivados num ou noutro dispositivo. Eventualmente, como sucede nessas hipóteses, seja válido, assim, recorrer ao texto legal maior, do qual efluem as premissas do sistema. Por exemplo, ao Art. $6^{\circ}$ da Constituição Federal, que veicula uma pauta exemplificativa dos direitos sociais (BRASIL, 1988), coadunados com o direcionamento de um agir socialmente responsável. Para esses direitos, não há que se selecionarem destinatários, como não há que se condicionar seus efeitos a qualquer elemento mediatário.

Note-se, no entanto, como já ponderado, que, quando as instituições não se movem pela finalidade de restarem cumpridos tais direitos, não há sanção legal que lhes possa ser cominada. Aí se encontra um ponto de influência do posicionamento jurídico da RSE sobre seu conceito corrente. A zona opaca em que se acha o conceito tem seu germe, pois, na sua própria nominação. Trata-se mesmo de responsabilidade? Para pensar essa questão, é necessário considerar que a responsabilidade social impõe uma punibilidade colhida no plano da interação social, como, por 
exemplo, a perda de credibilidade.

Na Lei 6.404/1976, conhecida por Lei de Sociedades Anônimas (LSA) (BRASIL, 1976), o Art. 154 reconhece, embora de forma genérica, a atuação socialmente responsável.

Art. 154. O administrador deve exercer as atribuições que a lei e o estatuto the conferem para lograr os fins e no interesse da companhia, satisfeitas as exigências do bem público e da função social da empresa. [...].

$\S 4^{\circ} \mathrm{O}$ conselho de administração ou a diretoria podem autorizar a prática de atos gratuitos razoáveis em benefício dos empregados ou da comunidade de que participe a empresa, tendo em vista suas responsabilidades sociais.

A lei, manifestamente, impõe limites ao ato empresarial. Subentende-se, no quadro capitalista, que a empresa orienta-se, originariamente, para a maximização de resultados. É essa vocação nativa que a lei confina, estabelecendo uma espécie de "pode, desde que...". O parágrafo quarto transcrito, embora pareça dispensável, dado não ser usual considerar necessário que se autorize a prática do bem, previne os administradores de responsabilização por prática de ato de gestão que extrapola os contornos do objeto social estatutário.

A respeito do referido parágrafo, é proficiente relembrar, ainda, a explicação de Lautenschleger Júnior (2005, p. 87): “Ficam vedados, assim, como já o era à época da legislação de 1940, os chamados atos de liberalidade (a lógica da administração como mandatária dos proprietários), salvo se em favor dos empregados e/ou comunidade e em sintonia com os interesses da companhia e sua função social”.

Recentemente, também a Lei 13.303/2016 (BRASIL, 2016) tratou da RSE, desta feita como dever imposto às empresas públicas e sociedades de economia mista - um dever aberto, no entanto: “Art. 27. $\S 2^{\circ} \mathrm{A}$ empresa pública e a sociedade de economia mista deverão, nos termos da lei, adotar práticas de sustentabilidade ambiental e de responsabilidade social corporativa compatíveis com o mercado em que atuam" (BRASIL, 2016).

$\mathrm{Na}$ ordem jurídica, a RSE parece encontrar arrimo também no intento de persecução de equilíbrio social. No sistema legal brasileiro, consiste em meta relevante, pronunciada, por exemplo, na regulamentação das relações de consumo. O Código de Defesa do Consumidor (BRASIL, 1990) tenciona mecânicas pelas quais o poder da empresa é nivelado pelo significativo favorecimento da parte ocupante do polo oposto da relação. Assim também a RSE, conquanto sem imposição por regimento legal específico, representa uma resposta, exigível da empresa pela sociedade, por conta do poder desmedido que lograram as corporações em comparação com outras instituições.

Ainda nessa esteira comparativa, é conjecturável também supor a RSE como contrapeso aos custos sociais gerados pela atividade empresarial. Como posto anteriormente, a responsabilidade civil não é comutável pela social. Entretanto, dela se aproxima quando considerado o fundamento reparatório. A transcendência das obrigações legais consistiria, assim, na compensação prestada pela empresa por obra dos danos sociais inerentes à atuação empresarial. Essa ideia já fora 
considerada em Davis (1975).

Por ponderação lógica, cabe admitir, ademais, que a RSE, dirigindo-se à coletividade, volve-se, no caminho, à própria empresa. Num cenário de competição irrefreada, é do interesse da sociedade que a empresa, principal unidade produtiva nas sociedades capitalistas, tenha condições de se manter, sustentavelmente. É, na contemporaneidade, a empresa a figura responsável pelo guarnecimento de boa parte dos bens consumíveis, e, sendo esse um encargo de alta responsabilidade, sua supervivência deve ser controlada. Exigir que a empresa preserve o meio natural, por exemplo, não é algo pelo que se visa apenas o benefício da sociedade; ambiciona-se também a conservação da entidade empresarial, que, se devastado aquilo que, sob o ponto de vista da produção, é recurso, corre o risco de se extinguir.

Em resumo, o exame da RSE sob a perspectiva legal, embora parta da inexistência de um vínculo jurídico específico de comprometimento entre as partes envolvidas, aponta para um alinhamento, em vários pontos coerentes, entre RSE e o "espírito" do ordenamento. Em outras palavras, se não se pode identificar a RSE como premissa ou consequência específica de relação obrigacional estabelecida entre duas partes, nem por isso é possível assegurar que uma empresa consiga adequar-se ao ordenamento prescindindo do agir socialmente responsável.

\section{APORTES TEÓRICOS DA TAC}

O escopo da teoria da ação comunicativa consiste em desenvolver um conceito de razão baseado no ato comunicativo emancipatório, contrapondo-se à noção instrumentalista da razão. Pressupõe, assim, um sujeito epistêmico, no qual a capacidade de conhecer e de agir está atrelada à razão comunicacional. Sua ação central é, pois, a comunicativa, uma das categorias de que se vale este ensaio. A outra é a ação estratégica. Trata-se de tipos contrastantes, producentes, quando comparados, de uma distensão na qual se pode encontrar subsídio para o exercício de uma compreensão crítica da modernidade. As subseções subsequentes embasam-se na obra magna do autor, publicada em 1981.

\subsection{A ação comunicativa}

A ação comunicativa é a que se constitui pela interação. A linguagem é o meio de que se valem para gerar entendimento, e o mundo da vida, a tecedura em que se dá. Esse mundo não é apenas seu entorno; é também consequência do acúmulo de ações. Constitui-se, pois, de interpretações geradas no passado, operando como mitigador das possibilidades de desconsentimento. Dada a consolidação dessas interpretações, o mundo da vida é recheado de convicções. Tanto a expressão do sujeito que se pronuncia quanto a interpretação que faz o outro dependem de experiências prévias. O mundo da vida, portanto, enquadra a ação comunicativa, propicia que dela se gere entendimento.

Eles próprios, os indivíduos, estão cativos do mundo da vida. Como coloca Habermas (1987, p. 126), “os atores comunicativos estão sempre se movendo dentro do horizonte do 
mundo da vida; eles não podem sair dele". Distante do alcance da contestação, é um mundo que, incorporado pelo sujeito, a ele também se incorpora. Explica o autor: "os participantes não podem assumir, in actu, a mesma distância em relação à linguagem e à cultura que existe em relação à totalidade de fatos, normas ou experiências passíveis de compreensão mútua" (HABERMAS, 1987, p. 126). Pela ação comunicativa, os indivíduos ajustam seus planos individuais. Na relação com o mundo da vida, a ação comunicativa presta-se, segundo o autor, a escopos variados: preserva a herança cultural e modifica-a, agrega os indivíduos e gera solidariedade, constitui a identidade de indivíduos socializados. Complementarmente, ação comunicativa e mundo da vida, em plano teorético, constroem-se mutuamente.

Importam para a ação comunicativa as falas que se ambicionam válidas e cuja reivindicação de validade é criticável. Pressupõe-se, assim, nas relações que se estabelecem pela ação comunicativa, movimentos dialógicos, decorrentes de momentos que não estão dados, mas, distintamente, são suscetíveis a constantes e sequentes construções consensuais. As possibilidades críticas, em Habermas, coexistem em relação a elementos de verificação do que se considera válido, quais sejam: a compreensibilidade, a veracidade, a correção normativa e a sinceridade da enunciação. Juntos, esses elementos tocam a integralidade do conceito de mundo da vida, perspectivado em três segmentos de mundo: o objetivo, o social e o subjetivo. As pretensões de validade - verdade, correção e veracidade - dirigem-se a cada um desses mundos, pelas vias respectivas. Numa situação ideal de fala, seriam elas exercidas em uma interação livre, em que os indivíduos não são coagidos por coisa alguma, exceto a obrigação autoimputada de argumentar. Esse seria um diálogo inclusivo e igualitário, do qual participariam todos os interessados, em igualdade de condições, e os interesses aí estampados não seriam, nenhum deles, de quem quer que seja, inapeláveis e livres de críticas. No processo argumentativo a única coerção possível é a do melhor argumento.

\subsection{A ação estratégica}

Contrapõe-se à comunicativa a racionalidade instrumental, também nominada por racionalidade meio-fim - que dirige a ação estratégica. A ação regrada pela racionalidade instrumental é avaliada sempre em função dos resultados produzidos; portanto, após a irradiação dos seus efeitos no mundo. Diferentemente da ação comunicativa, cujo objetivo é o entendimento, a ação estratégica objetiva a adequação.

Assim como a ação comunicativa está para o mundo da vida, a estratégica está para os subsistemas. É nos subsistemas mediados por poder e dinheiro - respectivamente, o aparato estatal e o mercado - que a ação estratégica acha espaço profícuo para gerar utilidade e eficiência. É ação interessada, motivada por convicções voláteis. Sua finalidade é a maximização dos próprios meios em função dos fins impostos pelos sistemas. Segundo Habermas, "emergem domínios de ação formalmente organizados que, em última análise, não se integram mais pelo mecanismo de entendimento mútuo, desviam-se dos contextos do mundo da vida e coagulam-se numa espécie 
de sociabilidade livre de normas" (HABERMAS, 1987, p. 307). Em princípio distintos, dinheiro e poder operam de forma amalgamada. Estabelece-se, entre a economia e o Estado um vínculo de dependência. Esse fenômeno reforça a capilaridade da ação estratégica que, qual líquido, flui indiferente por subsistemas peculiares, como se iguais fossem.

A despeito da viva distinção entre o mundo da vida e a ambiência dos subsistemas, esses contextos fundem-se, modernamente, em zonas promíscuas: o mundo da vida foi, circunstancialmente, colonizado pelos imperativos sistêmicos. Desintegrados de um suposto todo, torna-se possível que os subsistemas avancem sobre o que remanesce. A sobreposição dos subsistemas ao mundo da vida reifica estruturas simbólicas na medida em que a linguagem pela qual se gera entendimento é substituída por outras formas de mediação. Em alguns momentos (e.g., HABERMAS, 1987, p. 147), Habermas associa a reificação a deformações do mundo da vida. Sua colonização dá ensejo a uma série de patologias, efeitos colaterais que afligem a sociedade e a personalidade. O produto desses efeitos verifica-se na alienação da liberdade humana. Observe-se o trecho:

Como a esfera privada é debilitada e desgastada pelo sistema econômico, assim também a esfera pública é acometida pelo sistema administrativo. O esgotamento burocrático e a dessecação dos processos de opinião espontâneos e de formação da vontade dão margem à manipulação da lealdade das massas [...] (HABERMAS, 1987, p. 325).

Concebidos o tipo de racionalidade em que se funda, a ambiência em que ocorre e suas características básicas, a ação estratégica apresenta-se, assim, manifestamente, como modelo avesso ao da ação comunicativa. É nessa antinomia que encontramos uma espécie de tensão desejada para pensar de modo crítico fenômenos que, modernamente, exibem-se ao espectador nebulosamente. É como se tem em conta a RSE. A julgar apenas pela forma como são anunciadas as ações pelas quais se exerce, pode-se iludir pela falsa obviedade de um fenômeno que, à medida que se despem suas aparências, vai-se, paralelamente, distanciando do inequívoco.

\section{RELEITURA DA RSE MEDIANTE O APORTE DA TAC}

A ética, seja a clássica seja a moderna, surge da questão que se põe ao indivíduo quando carecedor de orientação: que devo fazer? (HABERMAS, 1989). É certo que a clareza de tal autoquestionamento pode-se acanhar em função de componentes que não estão ao alcance imediato da consciência ${ }^{1}$. Manter minimamente vigorosa a questão "que devo fazer?" parece ser, no entanto, o caminho para pensar o desenvolvimento da RSE. Do que se trata afinal a RSE senão do que devem fazer as empresas? Não há que se falar em responsabilidade se não se ponderar ao menos uma orientação que se apresenta ao agir. É na ação, ou na correspondente omissão que em referência a ela se desenha, que se configura a responsabilidade. Nos princípios jurídicos

$1 \quad$ Ver, por exemplo Welsh e Ordóñez (2014). 
afirmativos dos bens que se reputam importantes para a comunidade, podem-se obter diretrizes para um agir socialmente responsável, embora não decorra este, no caso específico do ordenamento brasileiro, de vínculo obrigacional determinado que onera a empresa em relação a este ou àquele indivíduo ou agrupamento.

A RSE não nos parece, entretanto, dimanar diretamente de qualquer ordenamento. Representa-se por RSE um fenômeno difuso, abrigado sob um conceito vago, que se edifica ao balanço das conotações linguísticas que se vão a ele aderindo, aguçadas, de um lado, pela premência dos problemas sociais e, de outro, pelas próprias empresas, muitas vezes posicionadas no centro desses problemas. Imiscui-se, ainda, na conexão que se estabelece entre esses polos, um conjunto de atores irresolutos, portando objetivos os mais diversos, como governos atulhados que veem na RSE um mecanismo prático para se alterar a partilha de incumbências estatuídas por leis ultrapassadas e blindadas por processos legislativos deveras rígidos ou, ainda, organizações não governamentais cujos membros, como elas próprias, sobrevivem da fiscalização e denúncia de problemas carentes de clemência empresarial. A RSE surge, assim, da necessidade de fazer frente a problemas, não apenas sociais (como dá a entender o nome): problemas de legitimidade, sustentação e competitividade das empresas, problemas de alcance das competências governamentais, problemas de subsistência daqueles que firmam sua missão na defesa de direitos difusos e coletivos, problemas, enfim, de várias ordens implicadas socialmente.

Problemas práticos surgem sempre. Se não forem para eles arranjadas soluções, disso decorrerão consequências que não nos interessam. É o que ocorre - exemplifica Habermas (1989) - quando a bicicleta usada diariamente quebra. Entre variadas possibilidades de ação, busca-se tomar uma decisão racional, visando-se a meta interrompida pelo contratempo. É nesse quadro que se busca encarar, neste ensaio, sob o referencial e os debates acima explorados, o conceito de RSE. Empreende-se um enfrentamento que tem por princípio problemas fáticos, não qualquer espécie de elemento originário. Propõe-se, para tanto, com fins didáticos, que se pondere sobre a série de questões que se ordena a seguir.

Caso se assuma, como apontado acima, que a RSE não se origina especificamente de qualquer ordenamento jurídico, qual seria então sua relação com essa esfera autonomizada do plano dos subsistemas habermasiano? Ora, a legislação não se posiciona com clareza a respeito da RSE. É parca a respeito e, quando dela trata, não deixa de fazê-lo com certa dose de inocuidade. É o que se depreende do já mencionado Art. 154 da LSA. A Constituição Federal pauta as bases do agir responsável, mas não especificamente em relação à RSE, e sim a qualquer agir responsável; ali estão, pois, os fundamentos de uma responsabilidade geral. Portanto, sob o ponto de vista legal, considerando-se a ausência de regra específica que a determine e, ao mesmo tempo, a imprescindibilidade fática da RSE, um agir socialmente responsável apenas poderia ser assim declarado se coadunado com os preceitos fundamentais do ordenamento jurídico dentro do qual é considerado.

Note-se que, ante a perspectiva legal, a RSE não pode prescindir do ordenamento. $\mathrm{O}$ conceito é formatado justamente através da ótica do ordenamento. Assim se dá não apenas com 
a RSE senão também com qualquer fardo a que se atribua o sentido de uma responsabilidade. Logo, havendo norma específica ou não, a dinâmica de conceituação é a mesma: enquadra-se o fenômeno no ângulo da lei para a ela conformá-lo. Tal enquadramento opera, dessa forma, como condição para que o fenômeno ganhe vida jurídica e, consequentemente, passe a produzir os efeitos jurídicos do sistema que agora o autentica.

Entretanto, o fenômeno, neste caso (como em outros tantos), precede a preocupação legal. Tanto assim que, tradicionalmente, avalia-se um ato de RSE aquele que suplanta as obrigações legais imputadas à empresa (e.g., MONTANA; CHARNOV, 2005). Ocorre também, como desenhado no já apresentado modelo proposto em Carroll (1979), que responsabilidades legais sejam entendidas como apenas parte da RSE. De todo modo, é flagrante como, no âmbito da gestão, a dimensão normativa da RSE fica acanhada. Na medida em que se coloca o fenômeno para além da norma ou, ainda, quando o conceito a absorve, torna-se difícil para o Direito regulá-lo, e uma responsabilidade não normatizada tende a fragilizar-se. Conjectura-se que seja justamente desse disparate que surge a oportunidade de contar com o apoio da TAC para aprofundar a significação comumente outorgada à RSE.

Outra questão que se apresenta, então, é a seguinte: diante das duas categorias da TAC aqui utilizadas, seria possível encaixar categoricamente a RSE em uma delas?

A empresa atua no espaço dos subsistemas; é protagonista emblemática da ação estratégica. Convém considerar, no entanto, que a RSE não ocorre no âmbito específico da empresa. Não pode ser entendida apenas como resposta a pressões sociais, tampouco como mero efeito da delegação às empresas de funções até então exercidas pelo Estado. Há evidências de que níveis reduzidos de compliance (recorde-se que, nas definições clássicas, a conformidade às normas legais consiste em condição constitutiva da RSE) devem-se à ausência de participação das empresas na formulação das regulamentações produzidas pelo Estado (MALESKY; TAUSSIG, 2017). A RSE dimana, pois, do plano discursivo que se institui na relação triangular entre empresa, Estado e sociedade. É isso que confere sentido à questão, cuja resposta, não fosse isso, em nada extrapolaria os limites do óbvio. É também nesse ponto que se encontra subsídio para justificar a utilização da TAC na reflexão empreendida.

Para dar conta de uma eventual categorização, cumpre, primeiro, distinguir a RSE dos seus atos. A RSE é um conceito, para o qual, como exposto, não se tem à disposição uma definição clara. Os atos de responsabilidade praticados pela empresa, opostamente, têm contornos mais precisos, no mundo fático possivelmente identificáveis. Importa essa distinção porque se, por um lado, a RSE como ideia parece alinhar-se com a ação comunicativa, como ato é recorrentemente no campo da gestão, racionalmente - utilizada com fins estratégicos. Observe-se: “[...] que maiores indicadores de responsabilidade social e sustentabilidade, associados com maior lucro específico, no ano anterior, contribuem para elevar a persistência do lucro específico dessas entidades no mercado brasileiro" (MEDEIROS; MOL, 2017, p. 194). Da mesma forma: “A análise oferece uma teoria baseada no risco para as origens da vantagem competitiva entre empresas rivais inicialmente idênticas e elucida a evidência empírica da relação entre risco e lucratividade e as implicações de 
desempenho da RSE” (ROSS, 2014, p. 202).

Em outro artigo dos já citados McWilliams e Siegel, a primeira seção em destaque intitulase "Desenvolvimento Teórico da Responsabilidade Social Corporativa Estratégica". A frase final do seu primeiro parágrafo representa bem a ideia:

Dado que estamos preocupados principalmente com a criação e a captura de valor pela empresa, definimos responsabilidade social corporativa como qualquer atividade "responsável" que permite à empresa alcançar vantagem competitiva sustentável, independentemente do motivo (MCWILLIAMS; SIEGEL, 2011, p. 1481).

No campo da gestão, não ocorre apenas de ter a RSE seu sentido associado à utilidade, mas também ser seu conceito confundido com os efeitos - os atos de responsabilidade - que sua prática produz. Na medida em que se extraem do conceito, que é abstração, suas consequências empíricas para, momento seguinte, em prol delas descartá-lo, queda-se com um conceito acéfalo, cujas demarcações ficam quase que plenamente à mercê das forças prevalentes na disputa travada entre aqueles que têm interesse em seu controle. Quando isso ocorre, a RSE aproxima-se da ação estratégica. Está-se diante de um quadro em que a responsabilidade é promiscuída com a ação que dela própria dimana. Note-se: "definimos responsabilidade social corporativa como ações que promovem algum bem social, para além dos interesses da empresa e do que é exigido por lei” (MCWILLIAMS; SIGEL, 2001, p. 117, grifo nosso). Ainda: "em suas várias definições, o termo [referência à RSE] envolve uma ampla gama de atividades econômicas, legais e voluntárias" (CARROLL, 1979, p. 498, grifo nosso).

Essa é a forma fácil de perceber a RSE. É como as empresas costumam vender a ideia. Inclusive, nem sempre a ideia é representativa do que veicula em âmbito teórico. O rótulo de socialmente responsável pode, por exemplo, ser construído às custas de outras empresas integrantes da cadeia de suprimentos (DEVIN; RICHARDS, 2018). A empresa, em regra, lida com o grande público. Os conceitos precisam de materialização, de elementos palpáveis. É quando, ao encontro das necessidades da linguagem corporativa, a empresa comunica ações. Pode até ser o caso de que as ações sejam de fato debatidas comunitariamente. O conceito, no entanto, é atingido apenas mediatamente. A RSE como ação é manifesta; como conceito, oculta. Repare-se: “Alguns exemplos de ações de responsabilidade social corporativa incluem ir além das exigências legais na adoção de programa de gestão de recursos humanos progressistas, desenvolvimento de procedimentos de testes sem animais, reciclagem, redução da poluição, apoio a empresas locais e incorporação de produtos com atributos ou características sociais" (MCWILLIAMS; SIEGEL, 2001, p. 117).

Assim, quando na RSE se imprime a marca da utilidade, tende a ação a pautar-se por uma racionalidade do tipo instrumental. Se, por exemplo, prover informações sobre RSE ao mercado resultar em aumento de chance de captação de crédito $^{2}$, justificam-se as decisões. E se a relação fosse reversa? Como exposto, trata-se de uma ação avaliada de acordo com os resultados que desencadeia, uma ação estratégica, adequada. O objeto da ação não é propriamente seu conteúdo,

Como constatado em Almeida e Santos (2016). 
mas os resultados que produz. É válido qualquer conteúdo que conduza ao fim pretendido. Pacificação do relacionamento com stakeholders, conformação a expectativas sociais, inteligência tributária: seja o que for, no mundo corporativo, quase tudo se resume à vantagem competitiva. Daí a dificuldade de precisar o conceito pela ação: a ação é móvel. Qualquer rol mencionado será sempre exemplificativo.

A RSE não é gestada exclusivamente dentro da empresa. Embora não seja desarrazoado como também já se argumentou - enxergar no interior do sistema empresarial a intenção sistemática de controle do seu conceito, cumpre ter que a RSE emerge da relação pouco ordenada entre empresa, Estado e sociedade. Por vezes, acrescem-se a essa desordem contradições subsistentes no campo de cada ator, como a coexistência de pressões conflitantes exercidas pelo Estado (LUO; WANG; ZHANG, 2017). É sob esse ângulo que se pode vislumbrar a RSE como fenômeno alinhado com a ideia representada pela ação comunicativa. Até na melhor mostra da literatura gerencial tradicional, na qual se busca imprimir a dose de ordem necessária a um tratamento instrumental, o conceito de RSE suscita confusão: "Essas pressões emergem de clientes, funcionários, fornecedores, grupos comunitários, governos e acionistas, especialmente institucionais. Com tantas metas e objetivos conflitantes, a definição de RSE nem sempre é clara" (MCWILLIAMS; SIEGEL, 2001, p. 117).

A RSE não é, contudo, como dá a entender a passagem citada - e isso já se disse -, apenas resposta a demandas sociais, embora significativamente também o seja. As empresas, em alguma medida, modelam essas demandas, uma vez que, muitas delas decorrem de problemas criados pelas próprias empresas. Pretende-se dizer: não se pode afirmar que a RSE começa necessariamente na sociedade - por que não na empresa? O que a sociedade faz, assumindo-se esse pressuposto subversivo, é responder a problemas pressionando a empresa por respostas. Cabe aí, no entanto, uma contraposição: a empresa não é a única responsável por criar demanda e os consequentes efeitos colaterais que provêm da oferta correlata; essa demanda é pressionada também pela sociedade e pelo Estado. É justamente quando se percebe a possibilidade dessa divergência que se realça o préstimo da categoria da ação comunicativa para apreciar a RSE. Vale colocar então outra questão: como explorar a RSE por essa orientação?

$\mathrm{Na}$ teoria habermasiana, a ação comunicativa ocorre como efeito da interação que se estabelece entre sujeitos. Não se está propriamente diante de um grande problema quando, assumindo-se a viabilidade teórica de operar a transferência do nível individual para o coletivo, se busca desvendar quem são os sujeitos interagentes no fenômeno da RSE - genericamente: empresa, Estado e sociedade. Ocorre, porém, não ser tão intuitivo compreender que a RSE inexiste senão como projeção conjunta dos discursos desses sujeitos. Note-se que se encontra aí um ponto de justificativa para a dificuldade de conceituação da RSE tanto no campo da gestão quanto na legislação. A ação comunicativa acontece no mundo da vida, que, constituído por interpretações produzidas no passado, se altera com o transcurso do tempo, e, por consequência, alteram-se também os discursos que nele se ambientam.

A conservação de elementos básicos da linguagem permite, no entanto, que a RSE seja, ainda que precariamente, apreensível como conceito. As convicções que ao mesmo tempo 
constituem o mundo da vida e são acolhidas pela legislação, por exemplo, fornecem parâmetros para a avaliação compartilhada do que se espera da atuação empresarial. Assim, a despeito de nebuloso, o conceito de RSE não deixa de ser passível de operacionalização pelos sujeitos envolvidos. Evidentemente, explorado o conceito pela via da ação comunicativa, não é possível enquadrar a RSE em uma noção absoluta, atemporal. É descabido falar aqui em essência. No mundo da vida, os sujeitos expressam-se e interpretam de acordo com suas experiências prévias. A teoria dos stakeholders, a despeito de coadunar-se com o agir estratégico, coloca em evidência a constante necessidade de diálogo entre as variadas partes que guardam interesse na atuação organizacional.

Mais apropriado falar aqui então em diálogo entre as partes que em diálogo da empresa com seus stakeholders. Isso porque, conforme se depreende da TAC, todo indivíduo é cativo do mundo da vida (HABERMAS, 1987). Quando se concebe a RSE por um viés unicamente estratégico, tende-se a avaliá-la como resultante exclusiva de movimentos opostos: de um lado, Estado e sociedade pressionando; de outro, a empresa respondendo - como se, tomando parte de mundos distintos, cada um agisse de acordo com lógicas próprias e contraditórias. A ideia de totalidade do mundo da vida parece alinhar-se mais à realidade fática, qual seja a de que todos estão envolvidos pelo mesmo mundo. Dessa ponderação decorre a possibilidade de declarar a RSE uma responsabilidade difusa, não unidirecional - no sentido da empresa para Estado e sociedade - mas partida de todos os atores envolvidos.

Como já se disse, não há que se falar em oferta sem a correspondente demanda. O termo "responsabilidade social" soa, nesse sentido, mais apropriado que o termo "responsabilidade social empresarial", inclusive porque evita que, continuamente, se construam teorias que, a despeito de direcionadas especificamente a uma das partes envolvidas na relação, se sustentam sobre bases teóricas semelhantes. Note-se:

Ética do consumidor/responsabilidade social tem sido adequadamente definida como $>$ os princípios morais e padrões que orientam os comportamentos dos indivíduos sobre como obter, usar e dispor de bens e serviços») (Muncy e Vitell 1992). Assim, seguindo essa definição, os consumidores têm pelo menos duas grandes responsabilidades. Em primeiro lugar, para com outros stakeholders, em suas relações [...]. Podemos chamar isso de responsabilidade ou ética de consumo. Em segundo lugar, para com a sociedade como um todo, os consumidores têm a responsabilidade de evitar o dano social [...]. Podemos chamar essa responsabilidade de responsabilidade social do consumidor (VITELL, 2015, p. 768).

A ideia de mundo da vida alinha-se, assim, pelo menos no sentido acima exposto, com a característica dispersão que marca o conceito de RSE. São os elementos simbólicos compartilhados pelas partes interagentes que conferem significação à RSE. O que se espera da empresa? Qual o papel do Estado? Que valores orientam o comportamento do indivíduo como membro da sociedade? São essas, entre um sem número de outras, questões que, avocando para si respostas compartilhadas 
pelas partes, configuram o conceito de RSE. Agora, a falta de clareza das pressuposições de que se valem os indivíduos para relacionar-se com o mundo torna precário o discurso que envolve a RSE, e essa precariedade tende tornar o conceito exposto a manipulações com fins perlocucionários.

O que se tem aí talvez se alinhe com a ideia representada em Habermas pela expressão “colonização do mundo da vida" (HABERMAS, 1987). A racionalização exacerbada da RSE torna-a plástica. Quando, em consequência disso, a relação entre as partes passa a ser mediada prevalentemente pela moeda, o mercado sobrepõe-se ao mundo da vida, e a RSE instrumentalizase. Então, a RSE, que, como fenômeno difuso, poderia constituir-se pela ação comunicativa, é impregnada de racionalidade econômica e viabiliza-se apenas quando as ações que dela decorrem adquirem alguma acepção racional teleológica. A literatura gerencial é farta a respeito. Note-se a apresentação desta proposta de pesquisa: "Propomos uma metodologia que permite aos gestores determinar o nível apropriado de investimento em RSE, com base em uma teoria da perspectiva da empresa" (MCWILLIAMS; SIEGEL, 2001, p. 118). Repare-se, ainda, neste objetivo geral: “[...] o objetivo deste artigo é explorar as implicações financeiras de determinadas características da nomeação de um diretor de RSE” (WIENGARTEN; LO; LAM, 2017, p. 477).

A busca pelo consenso tende a ficar, desse modo, prejudicada. O ponto de vista da intersubjetividade definha-se na medida em que os interagentes consideram-se pariformes, tornando-se, em decorrência, inexpressivos. Se, por exemplo, o Estado promiscui-se com empresas que viabilizam sua estrutura de funcionamento, o que resta de dissenso a ser debatido entre as partes (Estado e empresa)? Do mesmo modo, se a sociedade conforma-se excessivamente aos modelos propalados pelas empresas, quão distintas serão as posições de cada parte (sociedade e empresa)? Saliente-se que a intersubjetividade condiciona-se à existência de subjetividades. Aquela identidade de indivíduos socializados, cuja constituição integra o escopo da ação comunicativa, resta comprometida quando o mundo da vida é reificado e a ação estratégica invade âmbitos próprios da ação comunicativa.

Será que, conforme os parâmetros da ação comunicativa, se ambicionam válidos os enunciados dos interagentes quando engajados na RSE? Uma vez parametrizada por índices de elevado potencial de impacto, como os referenciados DJSI e ISE, em que medida a RSE ainda se oferece ao diálogo aberto entre os interagentes? Cabe lembrar que cada momento, na ação comunicativa, está sujeito a reformulações consensuais. Necessário para tanto, porém, que as partes mantenham-se adeptas das pretensões de validade da fala - o que não parece muito próximo da realidade. A franqueza dos enunciados, por exemplo, não é fácil sustentar. Discursos empresariais genéricos aos quais correspondem ações muito específicas podem servir como escudo que encobre as contradições inerentes à atuação empresarial. É o caso de uma empresa que, hipoteticamente, se declara ambientalmente responsável por fomentar programas de reflorestamento, mas, ao mesmo tempo, agride o ambiente poluindo o ar.

Na medida em que a RSE é sistematizada por parâmetros - emergentes especialmente da modelagem do conceito pelas grandes organizações -, vale considerar também que se incorre no risco de mitigar a relevância, supondo-se a RSE constituída pela ação comunicativa, das dimensões 
objetiva, social e subjetiva do mundo da vida. Isso porque a padronização enrijece o conceito e, por consequência, distancia dele os pormenores da realidade. Como podem os interagentes compartilhar o conhecimento de fatos averiguáveis se entre eles subsiste um elevado grau de assimetria de informação? É o que ocorre, por exemplo, quando a relação se dá entre uma grande empresa que causa impactos negativos difusos e uma pequena comunidade remota que, a despeito de impactada, pouco conhece dos porquês do impacto sofrido. Nas atuais circunstâncias, nada impediria, porém, que a empresa, enquadrando-se nos parâmetros estabelecidos, fosse considerada socialmente responsável. A RSE, ganhando conotação estratégica, torna-se protocolar.

A literatura gerencial, quando expõe as limitações ou as facilidades de um tipo específico de empresa para enquadrar-se como socialmente responsável, revela o referido caráter protocolar da RSE. Note-se:

Conclui-se que o contexto da pequena empresa impõe barreiras para a prática da responsabilidade social, mas que o impacto do tamanho menor sobre a responsabilidade social deve variar de acordo com uma série de condições. A partir de uma análise crítica dessas condições, sugerem-se oportunidades para as pequenas empresas e elementos para superar as barreiras limitadoras (LEPOUTRE; HEENE, 2006, p. 257).

A despeito de se tratar, assim, de um conceito ainda turvo, é comum que a RSE se apresente como certa, subsidiando categorizações acuradas, como uma linha que supostamente separa umas

empresas de outras. É para isso, afinal, que se prestam os conceitos. Uma questão que cabe então ser colocada é a seguinte: quem tem exercido maior influência sobre a demarcação dessa linha? Quando a RSE é instrumentalizada como ação estratégica, é possível que a coordenação dos planos de ação seja substituída pela imposição dos planos prevalentes. Isso ocorrendo, é preciso cogitar que qualquer potencial emancipatório que eventualmente se vislumbre na RSE resta suscetível a sucumbir perante seu também potencial de dominação.

\section{CONSIDERAÇÕES FINAIS}

Este artigo aproxima-se do conceito de RSE multidisciplinarmente, apoiando-se no pensamento habermasiano. Como teoria crítica, a TAC impulsiona o desvendamento de questões não aparentes. Destacam-se, nesta seção final, algumas considerações sobressalentes. Elas dimanam do exercício reflexivo de associação entre a RSE e o caráter estratégico ou comunicativo que a assinala.

A empresa é, destacadamente, espaço da ação estratégica. Talvez não seja disparatado entendê-la como o produto mais distinto seu. As ações que dela partem são, por consequência, tendencialmente marcadas pela lógica instrumental. Uma questão que vem à tona quando se pensa a RSE é se ela parte da empresa ou da sociedade. No entanto, quando se aproxima o plano didático da realidade sondada, quase sempre se devem abandonar as convicções fornecidas pela polarização das possibilidades para se acatar algum continuum um tanto dúbio e desprovido de uma métrica 
passível de identificação exata. Assim, à questão apresentada provavelmente tenha-se que oferecer a resposta de que a RSE é labiríntica, estimulada por forças provenientes de dentro e de fora da empresa.

Relevante seria essa questão para o diagnóstico, em plano teórico, do tipo de ação a orientar a RSE: se comunicativa ou estratégica. Sua significância encolhe-se, no entanto, quando se considera a colonização do mundo da vida. Além disso, a apreciação da realidade apouca ainda mais o dualismo em que toca a questão. Se não o conceito, pelo menos a prática da RSE tem-se mostrado preponderantemente estratégica. A RSE é correntemente utilizada como instrumento que contribui para a gestão de conflitos entre empresa e stakeholders, e essa relação tende a ser gerida quase sempre de modo estratégico. Agora, a despeito do instrumentalismo que lhe marca, e da consequente nebulosidade dos seus contornos conceituais, haveria espaço na RSE para a ação comunicativa?

Cumpre ponderar que a RSE, embora tenha seu conceito em larga medida modelado pela empresa, não cabe inteiramente no sistema empresarial. A inconsistência de seu conceito, se por um lado potencializa sua gestão estratégica, porque viabiliza que se faça uso seu de modo conveniente e contingencial, por outro retira-o do controle da empresa, expondo-o a influências alastradas que acabam por modelá-lo também. É aí que, eventualmente, se pode ver uma RSE conciliada com o mundo da vida, aberta à ação comunicativa - talvez.

Diz-se talvez porque se está aqui diante de um sítio cinzento, no qual, a despeito de, pelo menos como possibilidade, subsistir a ação comunicativa, o mundo da vida está sempre sob ameaça, na iminência de ter partes suas tragadas por algum sistema. Pragmaticamente, parece ser sensato admitir que não se trata de identificar aí um tipo de ação em detrimento de outro, mas de considerar ser possível o redimensionamento da empresa e dos espaços por ela amoldados. Cuidase de empreita ousada, a ser manejada diretamente no conceito de empresa.

Conceber a exclusão da dimensão estratégica do âmbito da empresa seria algo ilusório. A empresa não apenas a recebe como também a gera, com ela confundindo-se. Assim, essa dimensão tende a contagiar tudo que a empresa toca. É o que ocorre com a RSE, cujo conceito tem sido, historicamente, impregnado do raciocínio estratégico. Cogitando-se, no entanto, a chance de um redimensionamento da empresa, pode-se conjecturar a inclusão da dimensão comunicativa no conceito de empresa e, a partir daí, a propagação do tipo de ação correspondente pelas relações nas quais a empresa se envolve. Talvez apenas assim seja possível falar-se, genuinamente, de uma RSE menos instrumentalizada.

Como se infere das discussões realizadas, a RSE não decorre de mero raciocínio lógico. Ao que parece, a RSE é admitida apenas em resposta a um cenário social deveras desarmônico, que tem escandalizado a quem se propõe a, apesar do albergamento da anormalidade no seio da normalidade, enxergar a realidade pela ótica do bom senso. O que se pretende afirmar aqui é que a RSE não deve ser interpretada como algo necessariamente salutar, mas como construto 
pragmaticamente necessário, difusa e contraditoriamente orientado para a preservação não apenas das causas envolvidas como também do poder que pôs os objetos seus em risco.

Cabe salientar que, não obstante as potencialidades decorrentes do emprego da filosofia habermasiana, é sempre possível que o movimento que se faz do plano filosófico ao fenômeno empírico esbarre em limitações. Noutros termos, a teoria habermasiana não foi produzida especificamente para a análise da RSE. Quando se apropria, então, dos seus elementos para determinada análise, incorre-se no risco de, conquanto se tentando respeitá-la em sua originalidade, promover adaptações à teoria, com a finalidade de nela "fazer caber" o fenômeno. Por outro lado, é a partir desses atrevimentos que a filosofia ganha em extensão, o que, particularmente para a proposta crítica habermasiana, parece ser algo relevante.

Para pesquisas futuras, veem-se como potencialmente proveitosos trabalhos que acessem os porquês, no âmbito da razão prática, de casos concretos de RSE. Dada a complexidade do fenômeno e a consequente dificuldade de se estabelecerem asserções definitivas, esses exercícios reflexivos poderiam ser conduzidos por abdução, partindo-se de premissas manifestas para se firmarem conexões com premissas menores e conclusões probabilísticas. Aprofundar, enfim, reflexões sobre possíveis relações entre temas associados à gestão organizacional, ao direito e a filosofia habermasiana parece ser um movimento do qual podem resultar pesquisas interessantes, que, para além de relevância teórica, propiciem também implicações práticas, gerenciais e jurídicas.

\section{REFERÊNCIAS}

AARONSON, Susan Ariel. "minding our business": what the United States Government has done and can do to ensure that U.S. multinationals act responsibly in foreign markets. Journal of Business Ethics, Dordrecht, v. 59, n. 1-2, p. 175-198, 2005.

ALMEIDA, Moisés Araújo; SANTOS, Joséte Florentino. Estrutura de capital e divulgação voluntária de Informações de responsabilidade social corporativa das empresas brasileiras. Revista de Ciências da Administração, Florianópolis, v. 18, n. 45, p. 109-126, 2016.

BELKAOUI, Ahmed. The impact of the disclosure of the environment effects of organizational behavior on the Market. Financial Management, Tampa, v. 5, n. 4, p. 26-31, 1976.

BRASIL. Lei $\mathbf{n}^{0}$ 6.404, de 15 de dezembro de 1976. Dispõe sobre as Sociedades por Ações. Brasília, DF: Presidência da República, 1976. Disponível em: http://www.planalto.gov.br/ ccivil_03/leis/L6404consol.htm. Acesso em: 11 mar. 2016.

BRASIL. [Constituição (1988)]. Constituição da República Federativa do Brasil de 1988. Brasília, DF: Presidência da República, 1988. Disponível em: http://www.planalto.gov.br/ ccivil_03/constituicao/constituicao.htm. Acesso em: 8 mar. 2017.

BRASIL. Lei no 8.078, de 11 de setembro de 1990. Dispõe sobre a proteção do consumidor e dá outras providências. Brasília, DF: Presidência da República, 1990. Disponível em: http://www. planalto.gov.br/ccivil_03/leis/L8078.htm. Acesso em: 12 mar. 2016.

BRASIL. Lei no 10.406, de 10 de janeiro de 2002. Institui o Código Civil. Brasília, DF: 
Presidência da República, 202. Disponível em: http://www.planalto.gov.br/ccivil_03/leis/2002/ L10406.htm\#art2044. Acesso em: 27 jan. 2016.

BRASIL. Lei $\mathbf{n}^{\mathbf{0}}$ 13.303, de 30 de junho de 2016. Dispõe sobre o estatuto jurídico da empresa pública, da sociedade de economia mista e de suas subsidiárias, no âmbito da União, dos Estados, do Distrito Federal e dos Municípios. Brasília, DF: Presidência da República, 2016. Disponível em: http://www.planalto.gov.br/ccivil_03/_ato2015-2018/2016/lei/113303.htm. Acesso em: 6 jan. 2018.

CAMPBELL, David; MOORE, Geoff; METZGER, Matthias. Corporate philanthropy in the UK 1985-2000: some empirical findings. Journal of Business Ethics, Dordrecht, v. 39, n. 1, p. 29$41,2002$.

CARROLL, Archie B. A three-dimensional conceptual model of corporate performance. Academy of Management Review, Ada, v. 4, n. 4, p. 497-505, 1979.

CHIN, M. K.; HAMBRICK, Donald C.; TREVIÑO, Linda K. Political ideologies of CEOs: the influence of executives' values on corporate social responsibility. Administrative Science Quarterly, Ithaca, v. 58, n. 2, p. 197-232, 2013.

DAVIDSON, Wallace N.; WORRELL, Dan L. The impact of announcements of corporate illegalities on shareholder returns. Academy of Management Journal, Champaign, v. 31, n. 1, 195-200, 1988.

DAVIS, Keith. Five propositions for social responsibility. Business Horizons, Bloomington, v. 18, n. 3, p. 19-24, 1975.

DEVIN, Bree; RICHARDS, Carol. Food waste, power, and corporate social responsibility in the australian food supply chain. Journal of Business Ethics, Dordrecht, v. 150, n. 1, p. 199-210, 2018.

MUN, Eunmi; JUNG, Jiwook. Change above the glass ceiling: corporate social responsibility and gender diversity in japanese firms. Administrative Science Quarterly, Ithaca, v. 63, n. 2, p. 409-440, 2018.

FREEMAN, R. Edward. Strategic management: a stakeholder approach. Massachusetts: Sage, 1984.

FRIEDMAN, Milton. The social responsibility of business is to increase its profits. New York Times Magazine, New York, p. SM17, 1970.

GIULIANI, Elisa. Human rights and corporate social responsibility in developing countries' industrial clusters. Journal of Business Ethics, Dordrecht, v. 133, n. 1, p. 39-54, 2016.

HABERMAS, Jürgen. The theory of communicative action: lifeworld and system: a critique of functionalist reason. Boston: Beacon Press, 1987. v. 2.

HABERMAS, Jürgen. Para o uso pragmático, ético e moral da razão prática. Tradução de Márcio Suzuki. Estudos Avançados, São Paulo, v. 3, n. 7, p. 4-19, 1989.

HAFENBRÄDL, Sebastian; WAEGER, Daniel. Ideology and the micro-foundations of 
CSR: why executives believe in the business case for CSR and how this affects their CSR engagements. Academy of Management Journal, Champaign, v. 60, n. 4, p. 1582-1606, 2017.

IDEC - INSTITUTO BRASILEIRO DE DEFESA DO CONSUMIDOR. Responsabilidade social é direito do consumidor. 2011. Disponível em: http://www.idec.org.br/consultas/dicas-edireitos/responsabilidade-social-e-direito-do-consumidor. Acesso em: 16 jul. 2016.

KORTEN, David C. When corporations rule the world. Connecticut: Kumarian Press, 1995.

LANGE, Donald; WASHBURN, Nathan T. Understanding attributions of corporate social irresponsibility. The Academy of Management Review, Nova York, v. 37, n. 2, p. 300-326, 2012.

LAUTENSCHLEGER JÚNIOR, Nilson. Os desafios propostos pela governança corporativa ao direito empresarial brasileiro: ensaio de uma reflexão crítica e comparada. São Paulo: Malheiros Editores, 2005.

LEPOUTRE, Jan; HEENE, A. Investigating the impact of firm size on small business social responsibility: a critical review. Journal of Business Ethics, Dordrecht, v. 67, n. 3, p. 257-273, 2006.

LUO, Xiaowei Rose; WANG, Danqing; ZHANG, Jianjun. Whose call to answer: institutional complexity and firms' CSR reporting. Academy of Management Journal, Champaign, v. 60, n. 1, p. 321-344, 2017.

MALESKY, Edmund; TAUSSIG, Markus. The danger of not listening to firms: government responsiveness and the goal of regulatory compliance. Academy of Management Journal, Champaign, v. 60, n. 5, p. 1741-1770, 2017.

MCWILLIAMS, Abagail; SIEGEL, Donald. Corporate social responsibility: a theory of the firm perspective. The Academy of Management Review, Ada, v. 26, n. 1, p. 117-127, 2001.

MCWILLIAMS, Abagail; SIEGEL, Donald. Creating and capturing value: strategic corporate social responsibility, resource-based theory, and sustainable competitive advantage. Journal of Management, Stillwater, v. 37, n. 5, p. 1480-1495, 2011.

MEDEIROS, Ayron Wanderley; MOL, Anderson Luiz Rezende. Tangibilidade e intangibilidade na identificação do desempenho persistente: evidências no mercado brasileiro. Revista de Administração Contemporânea, Maringá, v. 21, n. 2, p. 184-202, 2017.

MONTANA, Patrick J.; CHARNOV, Bruce H. Administração. 2. ed. Tradução de Cid Knipel Moreira. São Paulo: Saraiva, 2005.

ROSS, David Gaddis. Taking a chance: a formal model of how firms use risk in strategic interaction with other firms. The Academy of Management Review, Ada, v. 39, n. 2, p. $202-$ 226, 2014.

SCHREMPF-STIRLING, Judith; PALAZZO, Guido; PHILLIPS, Robert A. Historic corporate social responsibility. The Academy of Management Review, Ada, v. 41, n. 4, p. 700-719, 2016.

SISON, Alejo José G. Aristotelian citizenship and corporate citizenship: who is a citizen of the 
corporate polis? Journal of Business Ethics, Dordrecht, v. 100, n. 1, p. 3-9, 2011.

VITELL, Scott J. A case for consumer social responsibility. (CnSR): including a selected review of consumer ethics/social responsibility research. Journal of Business Ethics, Dordrecht, v. 130, n. 4, p. 767-774, 2015.

WAGNER, Rea; SEELE, Peter. Uncommitted deliberation? discussing regulatory gaps by comparing GRI 3.1 to GRI 4.0 in a political CSR perspective. Journal of Business Ethics, Dordrecht, v. 146, n. 2, p. 333-351, 2017.

WELSH, David T; ORDÓÑEZ, Lisa D. Conscience without cognition: the effects of subconscious priming on ethical behavior. Academy of Management Journal, Champaign, v. 57, n. 3, p. 723-742, 2014.

WIENGARTEN, Frank; LO, Chris K. Y.; LAM, Jessie Y. K. How does sustainability leadership affect firm performance? the choices associated with appointing a chief officer of corporate social responsibility. Journal of Business Ethics, Dordrecht, v. 140, n. 3, p. 477-493, 2017.

Como Citar: NOGUEIRA, Arnaldo José França Mazzei. BANWWART JÚNIOR, Clodomiro José. FAVORETO, Ricardo Lebbos.Problematizando o conceito de responsabilidade social empresarial: implicações de uma leitura multidisciplinar. Scientia Iuris. Londrina, v.24, n.1, p. 55-77, março 2020. DOI 10.5433/21788189.2020v24n1p55. ISSN 2178-8189.

Recebido em: 10/10/2019

Aprovado em: 01/03/2020 